\title{
HIMPUNAN LEMBUT DENGAN MENGGUNAKAN HIMPUNAN PARAMETER TUNGGAL
}

\author{
WIDIA WATI, NOVA NOLIZA BAKAR \\ Program Studi Matematika, \\ Fakultas Matematika dan Ilmu Pengetahuan Alam, Universitas Andalas, \\ Kampus UNAND Limau Manis Padang, Indonesia, \\ email : widiawi99@gmail.com
}

\begin{abstract}
Abstrak. Dalam menghadapi masalah yang mengandung ketidakpastian diperkenalkan konsep himpunan lembut. Jenis-jenis dari operasi himpunan lembut harus didefinisikan terlebih dahulu. Beberapa peneliti menunjukkan bahwa beberapa definisi dan sifat-sifat himpunan lembut yang didefinisikan tersebut memiliki kelemahan. Dalam mengatasi kelemahan tersebut, beberapa peneliti membuat kontribusi dengan melakukan modifikasi terhadap operasi himpunan lembut. Dalam hal ini, beberapa peneliti mendefinisikan himpunan lembut dengan menggunakan subhimpunan yang berbeda dari himpunan parameter untuk setiap himpunan lembut. Pada paper ini digunakan himpunan parameter tunggal sebagai suatu kontribusi terhadap himpunan lembut.
\end{abstract}

Kata Kunci: Himpunan lembut, himpunan parameter, himpunan parameter tunggal

\section{Pendahuluan}

Molodtsov [5] memperkenalkan konsep himpunan lembut sebagai perangkat matematika baru dalam menghadapi masalah yang mengandung ketidakpastian. Akhirakhir ini, teori himpunan lembut dan aplikasinya telah mengalami kemajuan yang sangat pesat. Dalam literatur, jenis-jenis dari operasi himpunan lembut harus didefinisikan terlebih dahulu dan kemudian baru bisa digunakan dalam teori himpunan lembut dan aplikasinya.

Operasi dan sifat-sifat himpunan lembut secara detail dikembangkan oleh Maji dkk. [4]. Namun, beberapa definisi dan sifat-sifat himpunan lembut tersebut memiliki kelemahan. Kelemahan tersebut sebagian besar telah ditunjukkan oleh Ali dkk. [1] dan Yang [8]. Untuk mengatasi kelemahan tersebut, Ali dkk. [1], Neog dan Sut [6], Sezgin dan Atagun [7], Zhu dan Wen [9], dan Cagman dan Enginoglu [2] membuat kontribusi terhadap himpunan lembut.

Dalam mendefinisikan himpunan lembut, peneliti-peneliti sebelumnya menggunakan subhimpunan-subhimpunan yang berbeda dari himpunan parameter untuk setiap himpunan lembut. Hal tersebut menimbulkan kelemahan dalam beberapa operasi dan sifat-sifat himpunan lembut. Untuk itu, Cagman [3] memberikan pendekatan baru terhadap himpunan lembut dengan menggunakan himpunan parameter tunggal untuk setiap himpunan lembut dalam mengatasi kele-mahan-kelemahan yang terdapat dalam himpunan lembut sebelumnya.

Pada paper ini akan dikaji kembali tentang himpunan lembut dengan meng- 
gunakan himpunan parameter tunggal yang ditulis oleh Cagman [3] sebagai suatu kontribusi pada teori himpunan lembut dan kemudian membandingkannya.

\section{Himpunan Lembut dengan Menggunakan Himpunan Parameter Tunggal}

Definisi 2.1. [5] Misalkan $U$ adalah himpunan semesta dan E adalah himpunan semesta parameter. Pasangan $(Q, E)$ disebut himpunan lembut (atas $U$ ), jika $Q$ adalah suatu pemetaan dari $E$ ke koleksi dari semua subhimpunan-subhimpunan dari himpunan $U$.

Dalam hal ini $Q$ disebut approksimasi fungsi dari himpunan lembut $(Q, E)$. Untuk setiap $x \in E$, himpunan $Q(x)$ disebut $x$-aproksimasi elemen dari himpunan lembut $(Q, E)$. Selain itu, himpunan lembut $(Q, E)$ atas $U$ dapat ditulis sebagai

$$
(Q, E)=\{(x, Q(x)): x \in E\} .
$$

Elemen-elemen dari himpunan lembut yang memiliki aproksimasi elemen kosong, biasanya tidak dituliskan. Dalam himpunan lembut dengan menggunakan himpunan parameter tunggal, penulisan $E$ dalam himpunam lembut $(Q, E)$ bisa dihapus, sehingga himpunan lembut $(Q, E)$ dapat ditulis sebagai himpunan lembut $Q$. Selain itu, koleksi dari semua himpunan lembut dengan menggunakan himpunan parameter tunggal dinotasikan dengan $\mathbb{S}$.

Contoh 2.2. Misalkan terdapat enam rumah dalam himpunan semesta $U=$ $\left\{h_{1}, h_{2}, h_{3}, h_{4}, h_{5}, h_{6}\right\}, E=\left\{e_{1}, e_{2}, e_{3}, e_{4}, e_{5}\right\}$ adalah himpunan parameter. Untuk setiap $i=1,2,3,4,5$, parameter-parameter $e_{i}$ menyatakan modern, cantik, mahal, strategis, dan dikelilingi pemandangan hijau. Jika $Q$ adalah himpunan lembut atas $U$, dengan

$Q\left(e_{1}\right)=\left\{h_{2}, h_{3}, h_{4}\right\}, Q\left(e_{2}\right)=U, Q\left(e_{3}\right)=U, Q\left(e_{4}\right)=\emptyset, Q\left(e_{5}\right)=\left\{h_{1}, h_{2}, h_{5}, h_{6}\right\}$, maka himpunan lembut $Q$ dapat ditulis sebagai

$$
Q=\left\{\left(e_{1},\left\{h_{2}, h_{3}, h_{4}\right\}\right),\left(e_{2}, U\right),\left(e_{3}, U\right),\left(e_{5},\left\{h_{1}, h_{2}, h_{5}, h_{6}\right\}\right)\right\} .
$$

Definisi 2.3. [3] Suatu Himpunan lembut $Q$ atas $U$ dikatakan himpunan lembut Null, ditulis $\mathbb{O}$, jika $Q(x)=\emptyset$ untuk setiap $x \in E$.

Definisi 2.4. [3] Suatu Himpunan lembut $Q$ atas $U$ dikatakan himpunan lembut absolut, ditulis $\mathbb{U}$, jika $Q(x)=U$ untuk setiap $x \in E$.

Definisi 2.5. [3] Misalkan $Q, R \in \mathbb{S}$. Himpunan lembut $Q$ adalah subhimpunan lembut dari himpunan lembut $R$, ditulis $Q \subseteq R$, jika $Q(x) \subseteq R(x)$ untuk setiap $x$ $\in E$.

Proposisi 2.6. [3] Jika $Q \in \mathbb{S}$, maka
(1) $\mathbb{O} \simeq Q$.
(2) $Q \stackrel{\widetilde{\simeq}}{\text {. }}$.
(3) $Q \subseteq \mathbb{U}$. 
Bukti. Proposisi ini dibuktikan dengan aproksimasi fungsi, untuk setiap $x \in E$.

(1) Karena $\emptyset \subseteq Q(x)$ untuk setiap $x \in E$, maka $\mathbb{O} \widetilde{\subseteq} Q$.

(2) Pembuktian untuk (2) dan (3) dapat dilakukan dengan cara yang sama.

Definisi 2.7. [3] Misalkan $Q, R \in \mathbb{S}$. Himpunan lembut $Q$ sama dengan Himpunan lembut $R$, ditulis $Q=R$, jika $Q(x)=R(x)$ untuk setiap $x \in E$.

Proposisi 2.8. [3] Jika $Q, R, T \in \mathbb{S}$, maka

(1) $Q \widetilde{\subseteq} R, R \widetilde{\subseteq} Q \Leftrightarrow Q=R$.

(2) $Q \stackrel{\widetilde{\subseteq}}{\widetilde{c}} R, R \underset{\widetilde{\subseteq}}{\widetilde{S}} Q \Rightarrow Q \widetilde{\subseteq} T$.

Bukti. Proposisi ini dibuktikan dengan menggunakan aproksimasi fungsi untuk setiap $x \in E$.

(1) $Q(x) \subseteq R(x), R(x) \subseteq Q(x) \Leftrightarrow Q(x)=R(x)$.

(2) $Q(x) \subseteq R(x), R(x) \subseteq T(x) \Rightarrow Q(x) \subseteq T(x)$.

Definisi 2.9. [3] Misalkan $Q, R \in \mathbb{S}$. Gabungan lembut dari $Q$ dan $R$, ditulis $Q \widetilde{\cup} R$ adalah suatu himpunan lembut atas $U$ dengan aproksimasi fungsi didefinisikan sebagai

$$
Q \widetilde{\cup} R: E \rightarrow P(U), Q \widetilde{\cup} R(x)=Q(x) \cup R(x) .
$$

Proposisi 2.10. [3] Jika $Q \in \mathbb{S}$, maka
(1) $Q \widetilde{\cup} Q=Q$.
(2) $Q \widetilde{\cup} \mathbb{O}=Q$.
(3) $Q \widetilde{\cup} \mathbb{U}=\mathbb{U}$.

Bukti. Proposisi ini dibuktikan dengan menggunakan aproksimasi fungsi untuk setiap $x \in E$.

(1) $Q(x) \cup Q(x)=Q(x)$.

(2) Pembuktian untuk (2) dan (3) dapat dilakukan dengan cara yang sama.

Definisi 2.11. [3] Misalkan $Q, R \in \mathbb{S}$. Irisan lembut dari $Q$ dan $R$, ditulis $Q \widetilde{\cap}$ $R$, adalah suatu himpunan lembut atas $U$ dengan aproksimasi fungsi didefinisikan sebagai

$$
Q \widetilde{\cap} R: E \rightarrow P(U),(Q \widetilde{\cap} R)(x)=Q(x) \cap R(x) .
$$

Proposisi 2.12. [3] Jika $Q \in \mathbb{S}$, maka
(1) $Q \widetilde{\cap} Q=Q$.
(2) $Q \widetilde{\cap} \mathbb{O}=\mathbb{O}$.
(3) $Q \widetilde{\cap} \mathbb{U}=Q$.

Bukti. Proposisi ini dibuktikan dengan menggunakan aproksimasi fungsi untuk setiap $x \in E$. 
(1) $Q(x) \cap Q(x)=Q(x)$.

(2) Pembuktian untuk (2) dan (3) dapat dilakukan dengan cara yang sama.

Proposisi 2.13. [3] Jika $Q, R \in \mathbb{S}$, maka

(1) $Q \widetilde{\cap} R=R \widetilde{\cap} Q$.

(2) $Q \widetilde{\cup} R=R \tilde{\cup} Q$.

Bukti. Proposisi ini dibuktikan dengan menggunakan aproksimasi fungsi untuk setiap $x \in E$.

(1) $Q(x) \cap R(x)=R(x) \cap Q(x)$.

(2) Pembuktian untuk (2) dapat dilakukan dengan cara yang sama.

Proposisi 2.14. [3] Jika $Q, R, T \in \mathbb{S}$, maka

(1) $Q \widetilde{\cap}(R \widetilde{\cap} T)=(Q \widetilde{\cap} R) \widetilde{\cap} T$.

(2) $Q \widetilde{\cup}(R \widetilde{\cup} T)=(Q \widetilde{\cup} R) \widetilde{\cup} T$.

(3) $Q \widetilde{\cap}(R \widetilde{\cup} T)=(Q \widetilde{\cap} R) \widetilde{\cup}(Q \widetilde{\cap} T)$.

(4) $Q \widetilde{\cup}(R \widetilde{\cap} T)=(Q \widetilde{\cup} R) \widetilde{\cap}(Q \widetilde{\cup} T)$.

Bukti. Proposisi ini dibuktikan dengan menggunakan aproksimasi fungsi untuk setiap $x \in E$.

(1) $Q(x) \cap(R(x) \cap T(x))=(Q(x) \cap R(x)) \cap T(x)$.

(2) Pembuktian untuk (2), (3), dan (4) dapat dilakukan dengan cara yang sama.

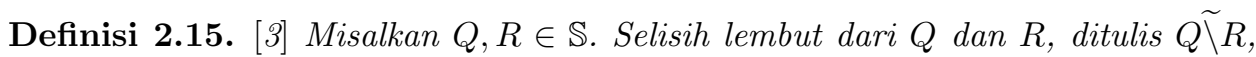
adalah suatu himpunan lembut atas $U$ dengan aproksimasi fungsi didefinisikan sebagai

$$
Q \widetilde{\backslash R}: E \rightarrow P(U),(Q \widetilde{\backslash R)}(x)=Q(x) \backslash R(x) .
$$

Proposisi 2.16. [3] Jika $Q \in \mathbb{S}$, maka
(1) $Q \widetilde{\searrow Q}=\mathbb{O}$.
(2) $Q \backslash \mathbb{O}=Q$.
(3) $\mathbb{O} \backslash Q=\mathbb{O}$.
(4) $Q \backslash \mathbb{U}=\mathbb{O}$.

Bukti. Proposisi ini dibuktikan dengan menggunakan aproksimasi fungsi untuk setiap $x \in E$.

(1) $Q(x) \backslash Q(x)=\emptyset$.

(2) Pembuktian (2), (3), dan (4) dilakukan dengan cara yang sama.

Definisi 2.17. [3] Misalkan $Q \in \mathbb{S}$. Komplemen lembut dari $Q$, ditulis $Q^{\tilde{c}}$, adalah suatu himpunan lembut atas $U$ dengan aproksimasi fungsi didefinisikan sebagai

$$
Q^{\tilde{c}}: E \rightarrow P(U),\left(Q^{\tilde{c}}\right)(x)=U \backslash Q(x)
$$


Proposisi 2.18. [3] Jika $Q \in \mathbb{S}$, maka
(1) $\left(Q^{\tilde{c}}\right)^{\tilde{c}}=Q$.
(2) $\mathbb{O}^{\tilde{c}}=\mathbb{U}$.
(3) $Q \widetilde{\cup} Q^{\tilde{c}}=\mathbb{U}$.
(4) $Q \widetilde{\cap} Q^{\tilde{c}}=\mathbb{O}$.

Bukti. Proposisi ini dibuktikan dengan menggunakan aproksimasi fungsi untuk setiap $x \in E$.

(1) $\left((Q(x))^{c}\right)^{c}=Q(x)$

(2) Pembuktian untuk (2), (3), dan (4) dapat dilakukan dengan cara yang sama.

Proposisi 2.19. [3] Jika $Q, R \in \mathbb{S}$, maka $Q \widetilde{\cap} R^{\tilde{c}}=Q \widetilde{\backslash} R$.

Bukti. Proposisi ini dibuktikan dengan menggunakan aproksimasi fungsi untuk setiap $x \in E$.

$$
\begin{aligned}
& \left(Q \widetilde{\cap} R^{\tilde{c}}\right)(x)=Q(x) \cap R^{\tilde{c}}(x), \\
& =Q(x) \cap(U \backslash R(x)), \\
& =Q(x) \cap\left(U \cap(R(x))^{c}\right), \\
& =Q(x) \cap(R(x))^{c} \text {, } \\
& =Q(x) \backslash R(x) \text {, } \\
& =(Q \widetilde{\backslash R})(x) \text {. }
\end{aligned}
$$

Proposisi 2.20. [3] Jika $Q, R \in \mathbb{S}$, maka berlaku hukum De Morgan.

(1) $(Q \widetilde{\cup} R)^{\tilde{c}}=Q^{\tilde{c}} \widetilde{\cap} R^{\tilde{c}}$

(2) $(Q \widetilde{\cap} R)^{\tilde{c}}=Q^{\tilde{c}} \widetilde{\cup} R^{\tilde{c}}$

Bukti. Proposisi ini dibuktikan dengan menggunakan aproksimasi fungsi untuk setiap $x \in E$.

(1) $(Q \widetilde{\cup} R)^{\tilde{c}}(x)=(Q(x) \cup R(x))^{c}=Q(x)^{c} \cap R(x)^{c}=\left(Q^{\tilde{c}} \widetilde{\cap} R^{\tilde{c}}\right)(x)$.

(2) Pembuktian untuk (2) dapat dilakukan dengan cara yang sama.

Contoh 2.21. Misalkan $U$ himpunan semesta dengan $U=\left\{h_{1}, h_{2}, h_{3}, h_{4}, h_{5}, h_{6}\right\}$ dan $E=\left\{e_{1}, e_{2}, e_{3}, e_{4}, e_{5}\right\}$ adalah himpunan parameter-parameter. Misalkan $Q$ dan $R$ adalah dua himpunan lembut atas $U$, dengan

$$
\begin{aligned}
& Q\left(e_{1}\right)=\left\{h_{2}, h_{3}, h_{4}\right\}, R\left(e_{1}\right)=\left\{h_{4}\right\}, \\
& Q\left(e_{2}\right)=U, R\left(e_{2}\right)=\left\{h_{2}, h_{3}, h_{4}\right\}, \\
& Q\left(e_{3}\right)=U, R\left(e_{3}\right)=U, \\
& Q\left(e_{4}\right)=\emptyset, R\left(e_{4}\right)=\emptyset, \\
& Q\left(e_{5}\right)=\left\{h_{1}, h_{2}, h_{5}, h_{6}\right\}, R\left(e_{5}\right)=\left\{h_{1}, h_{2}, h_{5}, h_{6}\right\},
\end{aligned}
$$

sehingga diperoleh himpunan lembut sebagai berikut: 
(a) $Q=\left\{\left(e_{1},\left\{h_{2}, h_{3}, h_{4}\right\}\right),\left(e_{2}, U\right),\left(e_{3}, U\right),\left(e_{5},\left\{h_{1}, h_{2}, h_{5}, h_{6}\right\}\right)\right\}$.

(b) $R=\left\{\left(e_{1},\left\{h_{4}\right\}\right),\left(e_{2},\left\{h_{2}, h_{3}, h_{4}\right\}\right),\left(e_{3}, U\right),\left(e_{5},\left\{h_{1}, h_{2}, h_{5}, h_{6}\right\}\right)\right\}$.

(c) $Q^{\tilde{c}}=\left\{\left(e_{1},\left\{h_{1}, h_{5}, h_{6}\right\}\right),\left(e_{4}, U\right),\left(e_{5},\left\{h_{3}, h_{4}\right\}\right)\right\}$.

(d) $R^{\tilde{c}}=\left\{\left(e_{1},\left\{h_{1}, h_{2}, h_{3}, h_{5}, h_{6}\right\}\right),\left(e_{2},\left\{h_{1}, h_{5}, h_{6}\right\}\right),\left(e_{4}, U\right),\left(e_{5},\left\{h_{3}, h_{4}\right\}\right)\right\}$.

(e) $Q^{\tilde{c}} \widetilde{\cap} R^{\tilde{c}}=\left\{\left(e_{1},\left\{h_{1}, h_{5}, h_{6}\right\}\right),\left(e_{4}, U\right),\left(e_{5},\left\{h_{3}, h_{4}\right\}\right)\right\}$.

(f) $Q^{\tilde{c}} \widetilde{\cup} R^{\tilde{c}}$ $\left\{\left(e_{1},\left\{h_{1}, h_{2}, h_{3}, h_{5}, h_{6}\right\}\right),\left(e_{2},\left\{h_{1}, h_{5}, h_{6}\right\}\right),\left(e_{4}, U\right),\left(e_{5},\left\{h_{3}, h_{4}\right\}\right)\right\}$.

(g) $Q \widetilde{\cap} R=\left\{\left(e_{1},\left\{h_{4}\right\}\right),\left(e_{2},\left\{h_{2}, h_{3}, h_{4}\right\}\right),\left(e_{3}, U\right),\left(e_{5},\left\{h_{1}, h_{2}, h_{5}, h_{6}\right\}\right)\right\}$.

(h) $(Q \widetilde{\cap} R)^{\tilde{c}}$ $\left\{\left(e_{1},\left\{h_{1}, h_{2}, h_{3}, h_{5}, h_{6}\right\}\right),\left(e_{2},\left\{h_{1}, h_{5}, h_{6}\right\}\right),\left(e_{4}, U\right),\left(e_{5},\left\{h_{3}, h_{4}\right\}\right)\right\}$.

(i) $(Q \widetilde{\cup} R)=\left\{\left(e_{1},\left\{h_{2}, h_{3}, h_{4}\right\}\right),\left(e_{2}, U\right),\left(e_{3}, U\right),\left(e_{5},\left\{h_{1}, h_{2}, h_{5}, h_{6}\right\}\right)\right\}$.

(j) $(Q \widetilde{\cup} R)^{\tilde{c}}=\left\{\left(e_{1},\left\{h_{1}, h_{5}, h_{6}\right\}\right),\left(e_{4}, U\right),\left(e_{5},\left\{h_{3}, h_{4}\right\}\right)\right\}$.

Definisi 2.22. [3] Misalkan $Q, R \in \mathbb{S}$. DAN-produk dari himpunan lembut $Q$ dan $R$, ditulis $Q \wedge R$, adalah operasi biner dari himpunan lembut atas $U$ dengan aproksimasi fungsi didefinisikan sebagai

$$
Q \wedge R: E \times E \rightarrow P(U),(Q \wedge R)(x, y)=Q(x) \cap R(y) .
$$

Definisi 2.23. [3] Misalkan $Q, R \in \mathbb{S}$. ATAU-produk dari himpunan lembut $Q$ dan $R$, ditulis $Q \vee R$, adalah operasi biner dari himpunan lembut atas $U$ dengan aproksimasi fungsi didefinisikan sebagai

$$
Q \vee R: E \times E \rightarrow P(U),(Q \vee R)(x, y)=Q(x) \cup R(y) .
$$

Proposisi 2.24. [3] Jika $Q, R, T \in \mathbb{S}$, maka

(1) $Q \vee(R \vee T)=(Q \vee R) \vee T$.

(2) $Q \wedge(R \wedge T)=(Q \wedge R) \wedge T$.

Bukti. Proposisi ini dibuktikan dengan menggunakan aproksimasi fungsi untuk setiap $x, y, z \in E$.

(1) $(Q \vee(R \vee T))(x, y, z)=Q(x) \cup(R(y) \cup T(z))=(Q(x) \cup(R(y)) \cup T(z)=$ $((Q \vee R) \vee T)(x, y, z)$.

(2) Pembuktian untuk (2) dapat dilakukan dengan cara yang sama.

Proposisi 2.25. [3] Jika $Q, R \in \mathbb{S}$, maka berlaku hukum De Morgan sebagai berikut

(1) $(Q \vee R)^{\tilde{c}}=Q^{\tilde{c}} \wedge R^{\tilde{c}}$.

(2) $(Q \wedge R)^{\tilde{c}}=Q^{\tilde{c}} \vee R^{\tilde{c}}$.

Bukti. Proposisi ini dibuktikan dengan menggunakan aproksimasi fungsi, untuk setiap $x, y \in E$,

(1) $(Q \vee R)^{\tilde{c}}(x, y)=(Q(x) \cup R(y))^{c}=Q(x)^{c} \cap R(y)^{c}=\left(Q^{\tilde{c}} \wedge R^{\tilde{c}}\right)(x, y)$.

(2) Pembuktian untuk (2) dapat dilakukan dengan cara yang sama. 


\section{Perbandingan Definisi-Definisi Himpunan Lembut}

(1) Perbandingan definisi himpunan lembut.

\begin{tabular}{|l|l|l|}
\hline $\begin{array}{l}\text { Menggunakan himpunan para- } \\
\text { meter tunggal }\end{array}$ & Cagman dan Enginoglu [2] & Maji dkk [4] \\
\hline$Q=\{(x, Q(x)): x \in E\}$ & $F_{A}=\{(x, F(x)): x \in E\}$ & $(F, A)=\{(x, F(x)): x \in A\}$ \\
\hline \begin{tabular}{l} 
dimana $\begin{array}{l}E \text { adalah himpunan semesta } \\
\text { dari parameter-parameter }\end{array}$ \\
\hline$Q: E \rightarrow P(U)$
\end{tabular} & $\begin{array}{l}\text { dimana } \\
A \subseteq E\end{array}$ & $A \subseteq E$ \\
\hline
\end{tabular}

(2) Perbandingan irisan himpunan lembut.

\begin{tabular}{|l|l|l|}
\hline $\begin{array}{l}\text { Menggunakan himpunan pa- } \\
\text { rameter tunggal }\end{array}$ & Cagman dan Enginoglu [2] & Maji dkk [4] \\
\hline$Q \widetilde{\cap} R=N$ & $F_{A} \widetilde{\cap} G_{B}=H_{A \cap B}$ & $\begin{array}{l}(F, A) \widetilde{\cap}(G, B)=(H, C) \\
\text { dengan } C=A \cap B\end{array}$ \\
\hline$N: E \rightarrow P(U)$ & $H:\left\{\begin{array}{l}A \cap B \rightarrow P(U) \\
(A \cap B)^{c} \rightarrow\{\emptyset\}\end{array}\right.$ & $H:(A \cap B) \rightarrow P(U)$ \\
\hline$N(x)=Q(x) \cap R(x)$ & $H(x)=F(x) \cap G(x)$ & $\begin{array}{l}H(x)=F(x) \text { atauG(x) (kedu- } \\
\text { anya aproksimasi elemen yang } \\
\text { sama) }\end{array}$ \\
\hline
\end{tabular}

(3) Perbandingan gabungan himpunan lembut.

\begin{tabular}{|c|c|c|}
\hline $\begin{array}{l}\text { Menggunakan himpunan pa- } \\
\text { rameter tunggal }\end{array}$ & Cagman dan Enginoglu [2] & Maji dkk [4] \\
\hline$Q \widetilde{\cup} R=M$ & $F_{A} \widetilde{\cup} G_{B}=H_{A \cup B}$ & $\begin{array}{l}(F, A) \cup(G, B)=(Y, I) \\
\text { dengan } I=A \cup B\end{array}$ \\
\hline$M: E \rightarrow P(U)$ & $H:\left\{\begin{array}{l}A \cup B \rightarrow P(U) \\
(A \cup B)^{c} \rightarrow\{\emptyset\}\end{array}\right.$ & $Y:(A \cup B) \rightarrow P(U)$ \\
\hline$M(x)=Q(x) \cup R(x)$ & $H(x)=F(x) \cup G(x)$ & $Y(x)= \begin{cases}F(x) & \text { jika } x \in A-B \\
G(x) & \text { jika } x \in B-A \\
F(x) \cup G(x) & \text { jika } x \in A \cap B\end{cases}$ \\
\hline
\end{tabular}

(4) Perbandingan komplemen himpunan lembut.

\begin{tabular}{|l|l|l|}
\hline $\begin{array}{l}\text { Menggunakan himpunan para- } \\
\text { meter tunggal }\end{array}$ & Cagman dan Enginoglu [2] & Maji dkk [4] \\
\hline$Q^{\widetilde{c}}$ adalah komplemen dari $Q$ & $\left(F_{A}\right)^{\widetilde{c}}=\left(F_{A}^{\widetilde{c}}\right)$ & $\left.(F, A)^{\widetilde{c}}=(F\rceil A,\right)$ \\
\hline$Q^{\widetilde{c}}: E \rightarrow P(U)$ & $F^{\widetilde{c}}:\left\{\begin{array}{l}A \rightarrow P(U) \\
A^{c} \rightarrow\{\emptyset\}\end{array}\right.$ & $\left.F^{\widetilde{c}}:\right\rceil A \rightarrow P(U)$ \\
\hline$Q^{\widetilde{c}}(x)=U \backslash Q(x)$ & $F^{\widetilde{c}}(x)=U-F(x)$ & $F^{\widetilde{c}}(x)=U-F(\neg x)$ \\
\hline
\end{tabular}
dimana $\neg x$ adalah bukan $x, \neg(\neg x)=x$ dan $\rceil A=\{\neg x: x \in A\}$.

(5) Perbandingan DAN-produk himpunan Lembut.

\begin{tabular}{|l|l|l|}
\hline $\begin{array}{l}\text { Menggunakan himpunan pa- } \\
\text { rameter tunggal }\end{array}$ & Cagman dan Enginoglu [2] & Maji dkk [4] \\
\hline$Q \wedge R=K$ & $F_{A} \wedge G_{B}=H_{A \wedge B}$ & $(F, A) \wedge(G, B)=(L, A \times B)$ \\
\hline$K: E \times E \rightarrow P(U)$ & $H:\left\{\begin{array}{l}A \times B \rightarrow P(U) \\
(A \times B)^{c} \rightarrow\{\emptyset\}\end{array}\right.$ & $L: A \times B \rightarrow P(U)$ \\
\hline$K(x, y)=Q(x) \cap R(y)$ & $H(x, y)=F(x) \cap G(y)$ & $L(x, y)=F(x) \cap G(y)$ \\
\hline
\end{tabular}

(6) Perbandingan ATAU-produk himpunan lembut.

\begin{tabular}{|l|l|l|}
\hline $\begin{array}{l}\text { Menggunakan himpunan pa- } \\
\text { rameter tunggal }\end{array}$ & Cagman dan Enginoglu [2] & Maji dkk [4] \\
\hline$Q \vee R=W$ & $F_{A} \vee G_{B}=H_{A \vee B}$ & $(F, A) \vee(G, B)=(O, A \times B)$ \\
\hline$W: E \times E \rightarrow P(U)$ & $H:\left\{\begin{array}{l}A \times B \rightarrow P(U) \\
(A \times B)^{c} \rightarrow\{\emptyset\}\end{array}\right.$ & $O: A \times B \rightarrow P(U)$ \\
\hline$W(x, y)=Q(x) \cup R(y)$ & $H(x, y)=F(x) \cup G(y)$ & $O(x, y)=F(x) \cup G(y)$ \\
\hline
\end{tabular}




\section{Kesimpulan}

Teori himpunanan lembut merupakan perangkat matematika baru dalam menghadapi masalah yang mengandung ketidakpastian. Dalam teori dan aplikasinya, penulis-penulis harus mendefinisikan operasi-operasi himpunan lembut terlebih dahulu dan kemudian baru bisa digunakan dalam teori himpunan lembut dan aplikasinya. Beberapa opersi dan sifat himpunan lembut memiliki kelemahan yang sebagian besar ditunjukkan oleh Ali [1] dan Yang [8]. Untuk mengatasi kelemahan tersebut, Ali dkk. [1], Neog dan Sut [6], Sezgin dan Atagun [7], Zhu dan Wen [9], dan Cagman dan Enginoglu [2] membuat kontribusi terhadap himpunan lembut. Dalam mendefinisikan himpunan lembut, peneliti-peneliti sebelumnya, diantaranya dalam [1], [6], [7], [9], dan [2] menggunakan subhimpunan-subhimpunan yang berbeda dari himpunan parameter untuk setiap himpunan lembut.

Dalam paper ini, dibuat kontribusi terhadap himpunan lembut yaitu hanya dengan menggunakan sebuah himpunan parameter tunggal untuk setiap himpunan lembut. Pendekatan baru ini membuat operasi dan sifat-sifat himpunan lembut jelas dan bebas dari kesulitan tanpa adanya kondisi yang diberikan.

\section{Ucapan Terima kasih}

Penulis mengucapkan terima kasih kepada Bapak Admi Nazra, Ibu Lyra Yulianti, Bapak I Made Arnawa, dan Ibu Yanita yang telah memberikan masukan dan saran sehingga paper ini dapat diselesaikan dengan baik.

\section{Daftar Pustaka}

[1] Ali, M.I, F. Feng, X. Liu, W.K. Min dan M. Shabir. 2009. On some new operations in soft set theory. Computers and Mathematics with Applications. 57: $1547-1553$.

[2] Cagman, N dan S. Enginoglu. 2010. Soft set theory and uni-int decision making. European Journal of Operational Research. 2072: 848 - 855.

[3] Cagman, N. 2014. Contribution to the theory of soft sets. Journal of New Results in Science. 4: $33-41$.

[4] Maji, P.K., R. Biswas dan A.R. Roy. 2003. Soft set theory. Computers and Mathematics with Applications. 45: 555 - 562.

[5] Molodtsov, D.A. 1999. Soft set theory first results. Computers and Mathematics with Applications. 37: 19 - 31 .

[6] Neog, T.J. dan D.M. Sut. 2011. A new approach to the theory of soft sets. International Journal of Computer Applications.

[7] Sezgin, A dan A. O. Atagun. 2011. On operations of soft sets. Computers and Mathematics with Applications. 61: 1457 - 1467.

[8] Yang, C.F. 2003. A note on "soft set theory" [Computers and Mathematics with Applications 45 : 555 - 562]. Computers and Mathematics with Applications 56 : $1899-1900$

[9] Zhu,P dan Q. Wen. 2013. Operations on soft sets revisited. Journal of Applied Mathematics. 2013: $1-7$. 